\title{
Corynebacterium striatum meningitis combined with suspected brain and lung abscesses: a case report and review
}

\author{
Ming-Jie Zhang, Xiao-Jie Cao, Jin Fan, Ze-Gang Yin and Ke Yu*
}

\begin{abstract}
Background: Intracranial infections with Corynebacterium striatum (C. striatum) have been described sporadically in the literature over the last two decades. However, C. striatum meningitis combined with multiple abscesses has not been published before.

Case presentation: In this report, we describe the clinical and imaging findings in a 54-year-old woman with meningitis caused by C. striatum and combined with suspected brain and lung abscesses. This patient who underwent multiple fractures and a recent cut presented with headache and paraphasia. C. striatum was isolated in cerebrospinal fluid and supposedly transmitted from the skin purulent wound through blood. The patient was treated with intravenous vancomycin and had a transient improvement, but died finally. Multiple abscesses, especially in the brain, could be a reason to explain her conditions were deteriorating rapidly.

Conclusions: Note that C. striatum can cause life-threatening infections. Early identification and diagnosis, early administration of antibiotics to which the bacterium is susceptible, and treatment of complications will be beneficial in patients with C. striatum-related infection.
\end{abstract}

Keywords: Corynebacterium striatum, Meningitis, Abscess, Case report

\section{Background}

Corynebacterium species are part of the resident skin flora. Among these, Corynebacterium striatum (C. striatum) is a kind of causative bacteria to induce various types of infections mainly including lower respiratory tract infection, isolated bacteremia and central line infections [1]. However, only a few reports have mentioned meningitis caused by $C$. striatum over the last two decades [2-5]. Furthermore, C. striatum meningitis combined with multiple abscesses has not been published before. In this report, we describe one patient with meningitis caused by $C$. striatum and combined with suspected brain and lung abscesses.

*Correspondence: yuke909@126.com

Department of Neurology, The General Hospital of Western Theater Command, No.270 Rongdu Avenue, Jinniu District, Chengdu 610083, Sichuan Province, People's Republic of China

\section{Case presentation}

A 54-year-old woman presented to the neurology department of our hospital on 29 October 2019 complaining of headache, blurred vision, vomiting and paraphasia. This patient had had rheumatoid arthritis and osteoporosis, and taken the drugs irregularly over the past decade. She broke her right femur 5 years ago and right leg 2 years ago. She underwent fracture repair surgeries successively and sustained the plate internal fixation in her right leg. The surgical wounds had healed without obvious infection. Accidentally, she cut her left leg over 40 days ago and smeared Chinese herbal ointment to promote healing. However, the treatment effect was poor and she had not paid enough attention to protect against infections. Ultimately, she left an unhealed and purulent wound

(c) The Author(s). 2020 Open Access This article is licensed under a Creative Commons Attribution 4.0 International License, which permits use, sharing, adaptation, distribution and reproduction in any medium or format, as long as you give appropriate credit to the original author(s) and the source, provide a link to the Creative Commons licence, and indicate if changes were made. The images or other third party material in this article are included in the article's Creative Commons licence, unless indicated otherwise in a credit line to the material. If material is not included in the article's Creative Commons licence and your intended use is not permitted by statutory regulation or exceeds the permitted use, you will need to obtain permission directly from the copyright holder. To view a copy of this licence, visit http://creativecommons.org/licenses/by/4.0/ The Creative Commons Public Domain Dedication waiver (http://creativecommons.org/publicdomain/zero/1.0/) applies to the data made available in this article, unless otherwise stated in a credit line to the data. 
visibly. Family and psycho-social history including relevant genetic information was normal.

At the time of admission, the patient's vital signs were normal without fever. She was confused and had simple language reaction to painful stimuli. She did not cooperate to complete neurological examination which showed a stiff neck and positive right pathological sign.

Laboratory tests of blood taken at admission showed a white blood cell (WBC) count of $14.61 \times 10^{9} / \mathrm{L}$ with $84.5 \%$ neutrophils. High-sensitivity C-reactive protein was $256.59 \mathrm{mg} / \mathrm{L}$ and procalcitonin was $4.89 \mathrm{ng} / \mathrm{mL}$, both far above normal values. Lumbar puncture was then performed after excluding contraindications, in especial brain shift on computed tomography $(\mathrm{CT})$ plain scanning. A lumbar puncture yielded cloudy cerebrospinal fluid (CSF) with initial pressure over $400 \mathrm{mmH}_{2} \mathrm{O}$. CSF analysis revealed an elevated total nucleated cell count of $1210 \times 10^{6} / \mathrm{L}$ (90\% multiple nuclear cells), an increased protein concentration of $1.58 \mathrm{~g} / \mathrm{L}$ (normal value, $0.01 \sim 0.45 \mathrm{~g} / \mathrm{L}$ ) and a decreased glucose concentration of $0.39 \mathrm{mmol} / \mathrm{L}$ (blood glucose $5.44 \mathrm{mmol} / \mathrm{L}$ ). Considering the available information, we empirically made a diagnosis of purulent meningitis and immediately treated with intravenous vancomycin $(1 \mathrm{~g}$ every $12 \mathrm{~h}$ ) and meropenem $(1 \mathrm{~g}$ every $8 \mathrm{~h}$ ) to cover all common causative microorganisms until culture results were known.

After a 24-h incubation period, gram staining of the cloudy CSF demonstrated the presence of gram-positive bacteria (Fig. 1). After $72 \mathrm{~h}$ of treatment, the patient had a marked improvement in health conditions and laboratory tests. She became alert, correct-replied and wellcooperated. In the meantime, her headache gradually relieved. Blood WBC count, high-sensitivity C-reactive protein and procalcitonin were all decreased. Total nucleated cell count of CSF for reexamination decreased to $110 \times 10^{6} / \mathrm{L}$, and CSF culture yielded no bacterial

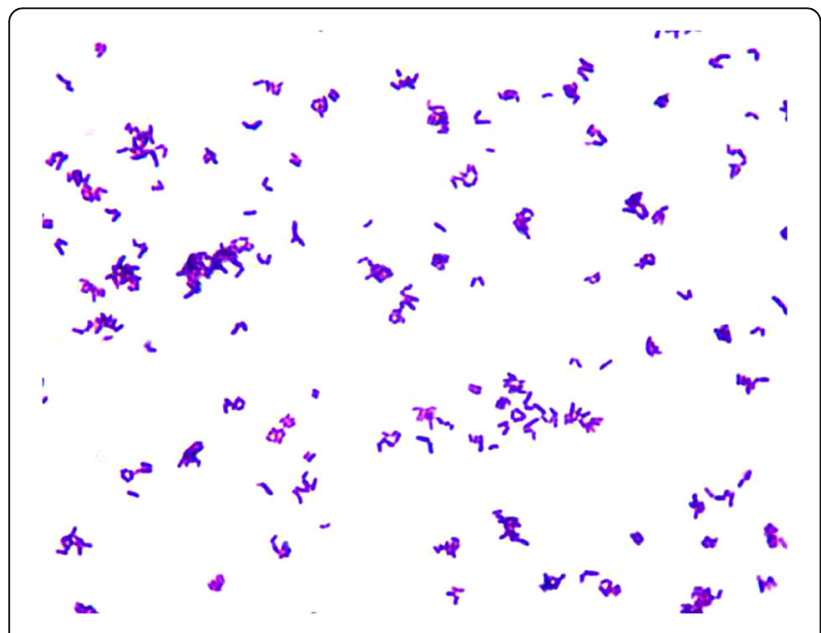

Fig. 1 Gram stain of C. striatum shows typical coryneform morphology growth. Five days later, the first bacterial culture was subsequently identified as Corynebacterium striatum (C. striatum). Susceptibility testing was not performed by our laboratory department due to a lack of drug sensitivity guidelines for this kind of bacteria in our country. Intravenous vancomycin and meropenem therapy was continued. Blood culture taken before the start of antibiotic therapy remained negative. The CSF and blood levels of vancomycin were not measured.

However, head and chest CT with contrast enhancement examinations (unable to complete magnetic resonance imaging, MRI) showed intracranial and pulmonary abnormal lesions, which were considered as abscesses (Fig. 2). After 9 days from admission, her conditions were deteriorating rapidly with coma and anisocoria. Dehydration therapy to decrease intracranial pressure was used immediately and the patient progressed smoothly to complete additional tests. A head CT was rearranged promptly and detected that the previous lesion was enlarged questionably. Considering that no definite brain shift was shown, we performed the lumbar puncture again to confirm CSF changes on the premise of the patient's conditions and her family's full consent. We followed the operating guidelines to reduce and slow the release of CSF. The lumbar puncture revealed cloudy CSF with initial pressure of $350 \mathrm{mmH}_{2} \mathrm{O}$, an increased total nucleated cell count of $536 \times 10^{6} / \mathrm{L}$ and protein concentration of $1.40 \mathrm{~g} / \mathrm{L}$. In the next day, this patient had respiratory and circulatory failure gradually. In spite of giving cardio-pulmonary resuscitation and mechanical ventilation, this patient eventually died. As far as available information was concerned, we speculated that the intracranial abscess ruptured and formed cerebral hernia. In the course of the hospitalization, the patient's family firmly refused any surgical operations because of the costs and risks.

\section{Discussion and conclusion}

C. striatum has been established as an emerging multidrug-resistant and opportunistic pathogen, which was traditionally known as a common component of the normal microbiota of skin and mucosal surfaces [1]. C. striatum was commonly isolated from wounds, respiratory specimens, tissue specimens, bone specimens and blood cultures. Therefore, most cases of C. striatum infection manifested as pneumonia, bacteremia/septicemia, endocarditis and peritonitis. And the scope of these infections has been broadening.

In the present case, C. striatum was isolated from CSF and identified as the causative pathogen. To our knowledge, only a few previous reports have implicated $C$. striatum in central nervous system infection. The first proven case of meningitis caused by $C$. striatum was published in 1996, which was a 23-year-old Canadian 


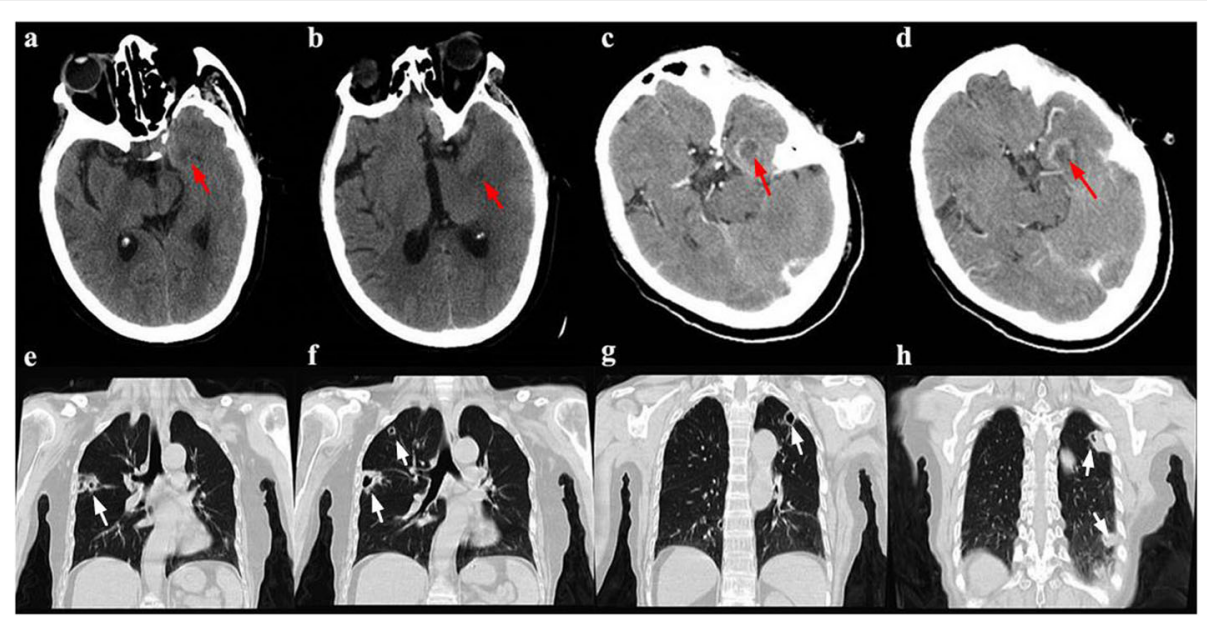

Fig. 2 Head (a-d) and chest (e-h) CT. CT plain scanning of the cranium (a-b, red arrow) shows a hypodense lesion in the medial temporal region. CT scanning with contrast enhancement (c-d, red arrow) shows the lesion characterized by a hypodense center and a hyperdense ring that is considered to be a suspected brain abscess. Chest CT scanning (e-h, white arrow) shows multiple and scattered cavitary lesions in peripheral lungs

man with a direct communication between the skin and the CSF through a catheter left after an extensive nerve reconstructive surgery [2]. Subsequently, the report from United Kingdom showed that the cultures of CSF samples yielded C. striatum from three children at the ages of 13-month, 20-month and 6-year, respectively [3]. These cases were all treated with a ventriculoperitoneal (VP) shunt and the cultures of VP shunt samples also revealed C. striatum. Two Turkish cases of meningitis due to $C$. striatum both underwent an external ventricular drainage after neurosurgery operations [4]. Additionally, a French man suffered a severe trauma leading to multiple craniocerebral injuries and skull fractures and subsequently had the C. striatum meningitis [5]. However, C. striatum meningitis combined with multiple abscesses has not been published before. Bacteria can enter the brain to induce intracranial infection through contiguous spread, hematogenous dissemination or with other unknown mechanisms [6]. After analyzing available literatures published, we discover the fact that there seems to be a direct communication between the skin and the CSF through the skin wound, bone fracture or drainage catheter to explain how C. striatum invades to CSF and causes meningitis. In the present case, it seemed that there was no direct communication between the skin and the CSF, in spite of those extracranial bone fractures. Hence, it suggested hematogenous spread of bacteria from the skin purulent wound was the primary cause of meningitis and forming abscess.

Cranial imaging should be performed in patients with intracranial infection, especially suspected brain abscess. CT scanning with contrast enhancement provides a rapid means to detect abscesses, but lacks sensitivity and specificity. Head CT scanning with contrast enhancement of the present patient showed the lesion characterized by a hypodense center and a hyperdense ring that was considered to be a suspected brain abscess. Comparatively, MRI combined with diffusion-weighted and apparentdiffusion coefficient images is a more valuable diagnostic tool [6]. Unfortunately, the present patient was unable to complete MRI because of the surgical plate in the body. The bacteria positive rate of CSF cultures in patients with brain abscess was not considerable, unless with coexisting meningitis [7]. Finally, the causative microorganism, $C$. striatum, in the present case was identified from CSF culture. However, the association between the C. striatum and abnormal lesion in brain was not definitely clear without evidence from biopsy or drainage culture. Additionally, pulmonary cavitary lesions on CT were detected in the present patient and abscesses could not be ruled out as well. The most common causes of lung abscess are aspiration pneumonia, transdiaphragmatic spread, and hematogenous seeding commonly associated with rightsided endocarditis or septic thrombophlebitis [8]. These cavitary lesions were multiple and scattered in peripheral lungs, which was more supportive of hematogenous spread of bacteria. Unfortunately, blood and sputum cultures were negative.

C. striatum is relatively resistant to many of the commonly used antibiotics with Gram-positive activity. It was demonstrated that vancomycin, linezolid and daptomycin were generally classified as active antibiotics [1] However, the failure of therapy with daptomycin in some case reports was associated with the rapid emergence of isolates with a resistant phenotype [1]. Vancomycin was found to be the universally used antibiotic in cases with $C$. striatum meningitis published in the above-mentioned studies and the present case report. 
Note that the different treatment effects and clinical outcomes were also attributed to severity of infection and patients' clinical manifestations. The fact that the present patient had coma, anisocoria, respiratory and circulatory failure associated with the intracranial infection could explain why she died. Multiple abscesses, especially in the brain, could be a reason that her conditions were deteriorating rapidly.

As a conclusion, these published cases confirm that $C$. striatum has the potential to cause meningitis especially in patients with direct communication between the skin and the CSF. No denying that hematogenous spread of C. striatum is also worthy of attention. The frequency of C. striatum infections appears to be increasing along with the improvement of feasibility and accuracy of the identification from clinical cultures. Note that C. striatum can cause life-threatening infections. Early identification and diagnosis, early administration of antibiotics to which the bacterium is susceptible, and treatment of complications will be beneficial in patients with C. striatum-related infection.

\section{Abbreviations}

C. striatum: Corynebacterium striatum; CSF: Cerebrospinal fluid; CT: Computed tomography; WBC: White blood cell

\section{Acknowledgements}

The authors gratefully acknowledge the patient's family for permitting us to disclose details relating to this case.

\section{Authors' contributions}

MJZ and KY were responsible for the patient's management during hospitalization. XJC, JF and ZGY participated in the diagnostics and treatment of the disease. MJZ, XJC and KY prepared the manuscript. All authors have reviewed and given significant contribution to the final version. All authors approved the final version of the manuscript.

\section{Funding}

This work was not financially supported.

\section{Availability of data and materials}

All data generated during this study are included in this published article.

\section{Ethics approval and consent to participate}

Not applicable.

\section{Consent for publication}

Written consent has been obtained from the patient's son and husband for publication of this case report.

\section{Competing interests}

The authors have declared that no competing interests exist.

Received: 4 March 2020 Accepted: 24 May 2020

Published online: 01 June 2020

\section{References}

1. McMullen AR, Anderson N, Wallace MA, Shupe A, Burnham C-AD. When good bugs go bad: epidemiology and antimicrobial resistance profiles of Corynebacterium striatum, an emerging multidrug-resistant, Opportunistic Pathogen. Antimicrob Agents Chemother. 2017;61(11):e01111-7.

2. Weiss $\mathrm{K}$, Labbe $\mathrm{AC}$, Laverdiere M. Corynebacterium striatum meningitis:case report and review. Clin Infect Dis. 1996;23(6):1246-8.

3. Hoy CM, Kerr K, Livingston JH. Cerebrospinal fluid-shunt infection due to Corynebacterium striatum. Clin Infect Dis. 1997;25(6):1486-7.
4. Sünbül M. Corynebacterium striatum meningitis: report of two adult cases Microb Ecol Health Dis. 2009;12(1):57-9.

5. Kammoun MM, Regaieg K, Bahloul M, Ammar R, Bouaziz M. Méningite à Corynebacterium striatum. Med Mal Infect. 2016:46(8):454-6.

6. Brouwer MC, Tunkel AR, McKhann GM, van de Beek D. Brain abscess. N Engl J Med. 2014;371(5):447-56.

7. Brouwer MC, Coutinho JM, van de Beek D. Clinical characteristics and outcome of brain abscess. Neurology. 2014;82(9):806.

8. Yazbeck M, Dahdel M, Kalra A, Browne A, Pratter M. Lung abscess: update on microbiology and management. Am J Ther. 2014;21(3):217-21.

\section{Publisher's Note}

Springer Nature remains neutral with regard to jurisdictional claims in published maps and institutional affiliations.
Ready to submit your research? Choose BMC and benefit from:
- fast, convenient online submission
- thorough peer review by experienced researchers in your field
- rapid publication on acceptance
- support for research data, including large and complex data types
- gold Open Access which fosters wider collaboration and increased citations
- maximum visibility for your research: over 100M website views per year
At BMC, research is always in progress.
Learn more biomedcentral.com/submissions 